DEVELOPMENT OF A MEASURE TO ASSESS QUALITY MANAGEMENT IN CERTIFIED FIRMS

\author{
Conca, Francisco José (francisco.conca@ua.es) \\ Llopis, Juan (juan.llopis@ua.es) \\ Tarí, Juan José (jj.tari@ua.es) \\ Department of Business Management \\ University of Alicante \\ Spain \\ Ap. Correos 99 \\ 03080 ALICANTE \\ SPAIN
}

Full address of the author to whom the page proofs are to be sent and the corresponding author:

Juan José Tarí

Departamento de Organización de Empresas

Facultad de Ciencias Económicas y Empresariales

Universidad de Alicante

AP. CORREOS 99

03080 Alicante

SPAIN

Telephone/fax: 34965903606

E-mail: jj.tari@ua.es 
DEVELOPMENT OF A MEASURE TO ASSESS QUALITY MANAGEMENT IN

\title{
CERTIFIED FIRMS
}

\begin{abstract}
The theory of quality management has been studied from different areas: quality leaders' ideas, empirical research and formal evaluation models. This has helped identify a set of critical factors for a successful implementation, as a way to improve customer satisfaction and performance.

Our study reviews the literature from these three points of view, in order to identify measures for change towards a quality culture, which can be empirically tested from the answers provided by those responsible for quality in 106 certified firms. The results yield a valid, reliable scale and provide empirical support so that managers know what to do in order to advance towards total quality management.
\end{abstract}

Keyword: Quality management; ISO 9000 certification; survey. 
DEVELOPMENT OF A MEASURE TO ASSESS QUALITY MANAGEMENT IN CERTIFIED FIRMS

\section{Introduction}

Total quality management (TQM) allows firms to obtain, on the one hand, a high degree of differentiation, satisfying customers' needs and strengthening brand image, and on the other, to reduce costs by preventing mistakes and waste of time and by making improvements in the corporation's processes. TQM requires a cultural change (Harber, Burgess and Barclay, 1993; Abraham, Fisher and Crawford, 1997; Guilhon, Martin and Weill, 1998; Dale, 1999) and the development of a number of components in an integrated way for a successful implementation (Powell, 1995; Easton and Jarrell, 1998).

In this respect, both researchers and managers have been interested in studying quality management, and identified a number of elements for a successful implementation. Thus, various studies have been carried out for the identification of those critical factors ensuring its success, as a way to develop a theory of quality management from three different areas: contributions from quality leaders (Crosby, 1979; Deming, 1982; Ishikawa, 1985; Juran, 1988; Feigenbaum, 1991), formal evaluation models (European Quality Award, Malcolm Baldrige National Quality Award, The Deming Award) and empirical research (Saraph, Benson and Schroeder, 1989; Flynn, Schroeder and Sakakibaru, 1994; Badri, Davis and Davis, 1995; Ahire, Golhar and Waller, 1996; Black and Porter, 1996; Grandzol and Gershon, 1998; Quazi et al., 1998).

Thus, managers need to understand what elements are necessary in order to change a firm's culture towards a quality culture. Starting from a review of these studies, the purpose of this paper is to contribute to: a) developing measures for change towards a quality culture and b) testing these measures for reliability and validity using answers from 
quality managers from 106 certified firms in the area of Alicante (eastern Spain).

This paper shall be structured as follows: firstly, we shall identify the critical factors of quality management through a review of the literature. Then, in the following section we shall study the metholodogy used in our research. Later, we shall provide the results of the reliability and validity studies, and we shall discuss and compare our results with those from other studies. Finally, we shall attempt to draw a number of conclusions.

\section{Critical factors in quality management}

Quality can be explained by examining their eight principal dimensions: performance, features, reliability, conformance, durability, serviceability, aesthetics and perceived quality (Garvin, 1988) and TQM from different bias. Quality management theory has been influenced by the contributions by quality leaders (Ishikawa, 1976, 1985; Crosby, 1979; Deming, 1982, 1986; Juran, 1986, 1988; Feigenbaum 1991). The research by all these authors shows both strengths and weaknesses, for none of them offers all the solutions to the problems encountered by firms (Dale, 1999), although some common issues can be observed, such as management leadership, training, employees' participation, process management, planning and quality measures for continuous improvement.

These ideas have exerted an influence upon later studies, in such a way that the literature on quality management has progressively developed from these initial contributions, identifying different elements for effective quality management. Taking the initial research as a basis, the critical factors in TQM found in the literature vary from one author to another, although there is a common core, formed by the following requirements:

- Customer-based approach.

- Management commitment and leadership.

- Quality planning. 
- Management based on facts.

- Continuous improvement.

- Human resource management (involvement of all members in the firm, training, work teams and communication systems that eliminate communication barriers).

- Learning.

- Process management.

- Cooperation with suppliers.

Alongside these factors, identified both in theoretical and empirical studies, there are standardized quality models used by firms in practice as a guide for their implementation, or in order to carry out self-evaluations of their quality practices. The main models are the Malcolm Baldrige National Quality Award model in the USA, the European Foundation for Quality Management (EFQM) model in Europe and the Deming Application Prize model in Japan.

In this line of work, we should refer, on the one hand, to the studies by Anderson, Rungtunsanatham and Schroeder (1994), who strive to synthetize a theory of quality management from a research based on the Delphi method, carried out both on academics and on managers closely related with quality, and using questions related to Deming's fourteen principles. From their conclusions they obtained seven concepts which form Deming's quality management theory: forward-looking leadership, internal and external cooperation, learning, administrative processes, continuous improvement, employees' performance and customer satisfaction. On the other hand, Kanji's Business Excellence Model (Kanji, 1998; Kanji and Moura e Sá, 2002) which propose the development of a framework integrating the critical success factors of TQM based on a set of principles and core concepts to achieve business excellence.

Together with these studies, there have been so far a number of contributions 
yielding a valid, reliable measurement tool to suitably evaluate these factors, which can help both researchers and managers who have to make decisions related to quality management. Firstly, we may quote the studies developing an instrument for measuring quality management, assessing its validity and reliability, applicable only to service firms, defined as SERVQUAL (Parasuraman, Zeithaml and Berry, 1985, 1988) or to industrial firms (Flynn, Schroeder and Sakakibara, 1994; Ahire, Golhar and Waller, 1996); and secondly, the studies which develop a valid, reliable quality measurement instrument, applicable to industrial and services firms (Saraph, Benson and Schroeder, 1989; Badri, Davis and Davis, 1995; Black and Porter, 1995, 1996; Grandzol and Gershon, 1998; Quazi et al., 1998), shown in Table I.

\section{“Table I”}

This examination allows us to say, on the one hand, that the critical factors of TQM differ from one author to another and, therefore, there is no unanimous view of the key factors of TQM, and on the other hand, that in practice firms may follow known, accepted, standard models as a guide to carry out quality management. In spite of this, this review shows that there are common issues appearing in the three approaches analyzed, such as leadership, quality planning, human resource management (training, teamwork, ...), customer focus, process management, suppliers management and continuous improvement (information, analysis, ...). They are those containing the view by the different authors and models cited, which we used for our research. This research also includes the learning category because, although it does not appear as such in the other works cited, it is interesting due to the recent studies in quality management pointing out its relevance (Anderson, Rungtusanatham and Schoroeder, 1994; Sitkin, Sutcliffe and Schoroeder, 1994; 
Hackman and Wageman, 1995; Dervitsiotis, 1998), and it also includes the 2000 review of the EFQM model (EFQM, 2000).

\section{Methodology}

\subsection{Sample}

In order to achieve our objective, we selected as the population for our study those firms carrying out their activity in the Alicante area (eastern Spain) which have received the ISO 9000 certificate. We selected certified firms because we wanted firms with some kind of quality system for the following reasons: a) these firms had one person engaged, either full time or part-time, in quality tasks and b) these organizations would be firms with a first level of TQM (Dale, 1999; Van der Wiele, Williams and Dale, 2000a), which is an objective criterion guaranteeing that these firms do possess a quality system. Also, the ISO 9000 quality management system, as the excellence models, is improving the understanding of concepts and practices associated with TQM (Van der Wiele, Dale and Williams, 2000, Van der Wiele, Williams and Dale, 2000b) and implies compliance with certain requirements of TQM, which may help to understand the questions asked, and therefore, to obtain adequate answers.

Thus, we requested a list of certified firms in the Alicante area from the organizations in charge of certification in Spain. In this way, the total population (number of certificates) was 175 . However, our study only includes 154 cases for the following reasons:

- We eliminated two multinational consultancy firms, which were not included in the study.

- There were four firms with more than one certificate for each of them (9 altogether), and thus the number of answers received was 4. 
- It was detected in some cases that there were various certified firms belonging to the same group, and thus the person responsible for quality matters was the same. This reduced a total of 22 certificates to 8 interviews (i.e. 8 answers).

In addition to this, it proved impossible to obtain data from 12 firms, and thus the final population considered was 142. The number of answers recorded was 108, which represents a response percentage of $76.06 \%$. However, two answers were not regarded as valid due to incomplete data; therefore, the number of cases processed statistically with the SPSS software was 106 firms. The characteristics of these 106 firms are those shown in Table II.

“Table II”

One sample-related error is that caused by the lack of response by some firms. Therefore, in order to verify if the lack of response was significant, we carried out a comparison between the firms that did answer and those which did not. It was seen that there were no significant differences between them regarding the variable size $(p=0.697)$ and sector $(\mathrm{p}=0.609)$. Also, the sampling error was \pm 0.049 .

\subsection{Data collection}

While the database was being selected, a questionnaire was designed meeting the objectives that had been set. The process of developing the questionnaire finished with a pilot survey, which was used to modify and eliminate a number of variables, until the final questionnaire was designed. Experts on the subject were consulted, to ensure that the questions were properly phrased, and the suitability of the questionnaire was tested on a sample of firms (Madu, 1998). In this way, this test consisted of a first revision of the 
questionnaire (pre-test) with four people (an academic, a small-medium firm manager and two quality consultants), to ensure a suitable coverage of the domain of each construct, and a second test with the ten first firms studied, selected at random, which allowed us to modify and delete some variables.

The data were collected by means of a structured personal interview, carried out face to face, based on a closed questionnaire, plus a set of open questions which allowed us to clarify certain points. We decided to combine the interview with the questionnaire and, due to the need for personal interaction, the participating firms were limited to the Alicante area.

Thus, we conducted the interviews with the firms that agreed to participate. The questionnaire was answered by the persons in charge of the quality area, for these reasons: a) these persons play an active role in the quality strategy; b) they possess the knowledge required to answer the questionnaire, and given their training and knowledge on the subject, considering that these firms had quality systems, this would allow a better understanding of the questions; and c) in similar studies, the key person to interview is the quality manager.

\subsection{Measures}

We carried out a review of the literature in order to identify critical factors. Our measures are based on the EFQM model and on a review of the literature. We selected the measures considering the enablers defined by the EFQM model and on a review of the literature, defining the items from those fixed in that model and on the empirical work by Saraph, Benson and Schroeder (1989), Badri, Davis and Davis (1995), Black and Porter (1995, 1996), Powell (1995), Ahire, Golhar and Waller (1996), Grandzol and Gershon (1998) and Quazi et al. (1998). 37 items were used in our final questionnaire, grouped within eight factors and measured within a 7-point scale (Table III; Appendix I). 
“Table III”

Besides, we were interested in verifying whether there was a connection between the implementation of a quality system and quality performance; therefore, two dimensions were included, one related to customer satisfaction and another to performance in TQM (Appendix II), the first one with an alpha coefficient of 0.56 and the second one of 0.82 . We have based ourselves on the customer satisfaction construct used by Grandzol and Gershon (1998) and on the performance construct of the TQM program used by Powell (1995); however, in both factors we have included in the final questionnaire one item less than in these studies, such item being dropped in the pilot test. The two measurements are averaged, thus obtaining the measurement of the performance of quality management.

Concerning the TQM program performance construct, the effects of quality on performance may be evaluated by examining unexpected changes in published financial results, for example, in the five years following the introduction of quality management (Easton and Jarrell, 1998); or in a subjective way, by measuring respondents' perceptions. Such subjective measurements are widely accepted in organizational research (Powell, 1995), due to the difficulty of identifying and obtaining an objective measurement for firms of different sizes and sectors (Saraph, Benson and Schroeder, 1989). In our case, we chose the second option and we measured the results through seven items each on a seven-point scale. As for the customer satisfaction construct, we used a variable consisting of three items measuring the level of customer satisfaction.

\section{Development of measures TQM}

With the data collected from the 106 firms, the reliability and validity of the 
measures must be verified. In this sense, the studies reviewed in Table I follow similar methods to create a valid, reliable instrument to measure critical factors in TQM. We identify three methods in the development of an instrument for measuring TQM: a) the methodology used by Saraph, Benson and Schroeder (1989), Badri, Davis and Davis (1995), Grandzol and Gershon (1998) and Quazi et al. (1998), b) the method by Black and Porter $(1995,1996)$ and c) the methodology used by Ahire, Golhar and Waller (1996).

After considering these methodologies, the first one was selected for our study, for it is a methodology developed by psychologists and it has been widely accepted in the development of an instrument for measuring variables in social sciences (Likert, 1967; Nunnally, 1978). In this case, we started with a revision of the literature, as we discussed in the critical factors in the quality management section (stage 1). Next, we identified the critical factors of successful TQM, as reflected in Table III (stage 2). Then, the initial items were selected (stage 3), a previous test was carried out (stage 4) to refine the measurement instrument (stage 5) and obtain the final questionnaire to be used in data collection (stage 6). The following stages are: reliability test (stage 7), detailed item analysis (stage 8) and validity analysis (stage 9), in order to develop measures of TQM.

\subsection{Reliability}

Although it can be measured in several ways, we shall follow the internal consistency method. This can be estimated by means of a reliability coefficient, such as Cronbach's alpha, measuring the internal consistency of multidimensional scales (Cronbach, 1951); this is the most widely used reliability estimate in empirical research (Peterson, 1994). In this respect, the minimum advisable level is 0.7 (Nunnally, 1978), although it may be reduced to 0.6 in exploratory research (Hair et al., 1995) or even to 0.55 (Van de Ven and Ferry, 1979).

For this purpose, we calculate the reliability for each set of items of the eight critical 
factors of TQM. Once the alpha has been obtained for the whole measure, it is recalculated after eliminating one item, in order to verify if the scale improves (Table IV).

“Table IV”

Thus, for example, the alpha coefficient for the leadership measure is 0.76 , and it can be seen that, after deleting the first item, the alpha coefficient (considering only the remaining items) is 0.77 , which is an improvement on the scale. Similarly, the scale improves after dropping the third item in the suppliers management scale. The other measures maintain their original form. Concerning customer focus measure, the alpha was less strong (0.54). In this context, the literature shows that there are significant differences in this coefficient, between using a two-category scale and more than two category scales (Churchill and Peter, 1984; Peterson, 1994), and there are no significant differences between using a Likert 1 to 5 scale and a 1 to 7 scale. Also, there is a tendency towards higher reliabilility and lower measurement error when the number of items is increased (Churchill, 1979). However, this is not a very strong relationship, and the greatest differences appear in scales between two and three items and those with more than three. 10-item scales have very high coefficients (Peterson, 1994); therefore, it seems that very high coefficients (higher than 0.9) should be avoided, for they might entail redundancy between the items (Boyle, 1991). By applying these ideas, and based on Van de Ven and Ferry (1979) the alpha for customer focus factor was acceptable. In this sense, Allen and Kilmann (2001) obtain an alpha of 0.54 for their "extrinsic rewards scale" and they consider it acceptable based on Van de Ven and Ferry.

The ratings are within the set limits, although they are slightly lower than those found in the works cited. In Saraph, Benson and Schroeder (1989) the alpha coefficient 
ranges between 0.71 and 0.94; in Badri, Davis and Davis (1995), between 0.89 and 0.97; in Black and Porter $(1995,1996)$ between 0.68 and 0.87; in Ahire, Golhar and Waller (1996), between 0.72 and 0.92; in Grandzol and Gershon (1998) between 0.73 and 0.86 and in the research by Quazi et al. (1998) between 0.82 and 0.95 .

\subsection{Detailed item analysis}

This analysis evaluates how the items are assigned to each scale, using each item's correlation with each scale (Nunnally, 1978). This correlation is used to determine whether an item belongs to the scale it has been assigned to, to a different one, or whether it should be eliminated. After eliminating the items mentioned in the reliability analysis, we calculate the correlation matrix for the remaining items and the 8 critical factors.

Only item 6 in the employee management measure (bottom-up, top-down and horizontal communication) has a correlation of 0.56 with the learning factor, higher than 0.51, which is the correlation it has with its scale; therefore, it must be eliminated because it has a higher correlation with a scale different from the original one. Thus, this variable was eliminated, and we concluded that the remaining items had been correctly assigned to the scales, because the highest correlations were found in the scales to which they had initially assigned.

\subsection{Validity}

The most widely accepted classification is the one distinguishing between content, criterion-related and construct validity, as reflected in the empirical research cited in the literature review concerning stages in the development of measuring instruments.

Content validity. An instrument has content validity if researchers agree that the instrument is made up of a group of items covering the issues to be measured, i.e. that it represents a specific thematic universe. This is a subjective evaluation, which we consider 
suitable because these critical factors in the evaluation of quality management have been obtained from a review of the literature and a pilot test as in the works cited in Table I.

Criterion-related validity. This is measured through the correlation coefficient with other measures, in such a way that it is useful to measure a present or future behavior. These 8 factors have a high criterion-related validity when, taken together, they are highly and positively related with a firm's quality performance. This type of validity is examined through the multiple correlation coefficient between the 8 factors and a measurement of the quality performance, which in our case is the average between the two variables (customer satisfaction and performance) defined in the methodology section.

The multiple correlation coefficient between the 8 critical factors of TQM and this measure is $0.55(\mathrm{p}=0.000)$, which indicates that these 8 factors are significantly related to quality performance, but in a moderate way, compared to the other studies. Saraph, Benson and Schroeder (1989) obtain a measure of 0.80; Badri, Davis and Davis (1995), 0.85; and Quazi et al. (1998), 0.73. Also, there are two studies using a correlation between individual scale and a quality performance. In this respect, Ahire, Golhar and Waller (1996) point out that all the scales have statistically significant positive correlations with a quality performanece and, therefore, criterion-related validity is accepted. Similarly, Grandzol and Gershon (1998) state that almost all the correlations exceed the acceptable rating of 0.30 .

Construct validity. This measurement is calculated through a factor analysis for each of the 8 factors. In this analysis, each factor must be one-dimensional. It can be observed that 6 are one-factor (Table V) and two are not (Tables VI and VII); the quality planning and employee management measures consist of two factors each. Each of these factors was determined to have adequate reliability (Szamosi and Duxbury, 2002). Cronbach alphas were: a) Factor $1=0.71$; Factor $2=0.78$ (planning factor) and b) Factor 1 $=0.79$; Factor $2=0.75$ (employee management factor). 
“Tables V, VI and VII”

In this respect, the research by Saraph, Benson and Schroeder (1989) shows that the process management factor is not one-dimensional, and concludes by indicating that future studies should consider the possibility of dividing the critical factor of process management into two separate constructs.

\section{Implications for managers}

Through a review of the literature we have identified eight factors of TQM, in order to develop a measure instrument whose reliability and validity is tested empirically. These studies show that the stated objective of identifying measures for change towards a quality culture and developing a valid, reliable scale has been achieved after eliminating the first item (higher management actively directs our quality program) in the leadership measure, the third one (management encourages the use of few suppliers, emphasizing quality rather than price) in the suppliers management factor, and the last one (bottom-up, top-down and horizontal communication) in the employee management measure. This has led us to identify 10 measures of TQM (Table VIII).

“Table VIII”

The 10 factors of TQM are the agents that may lead to satisfactory performance, as has been proved by other studies (Saraph, Benson and Schroeder, 1989, Badri, Davis and Davis, 1995; Ahire, Golhar and Waller, 1996; Grandzol and Gershon, 1998; Quazi et al., 
1998; Das et al., 2000). However, although the data show the existence of connections between factors of TQM and a firm's performance, it cannot be strictly proven that TQM causes increased performance, but simply that such relationship exists (Powell, 1995) and also that, as many respondents answered, quality may influence part of the firm's performance.

Certification could be useful to consumers as a sign of the good quality of the products offered by the companies (Nicolau and Sellers, 2002) and a competitive advantage to firms. However, such certification is merely one step towards TQM. If the main objective of the managers is to advance towards TQM, their efforts should be aimed toward the implementation of the $10 \mathrm{TQM}$ measures identified. These measures are applicable to certified firms in the Alicante area, because there are no significant differences between those firms which have been interviewed and those firms which have not; the measures may be applied by managers of certified firms in the area regardless of firm size and sector. In this respect, although the results cannot be extrapolated statistically to other firms in Spain or in Europe, a logical extrapolation (i.e. a generalization based on qualitative criteria) can be made, since the factors identified agree with those established in the EFQM model.

Our measures differ from those obtained by the works cited in that we have supplied empirical evidence on an issue which was not analyzed in such studies, as we used as our main source the criteria in the EFQM model and obtained data from a region in Europe. In this respect, Saraph, Benson and Schroeder (1989) worked with firms with over 1000 employees, which indicates that their model works well with large firms. Similarly, Ahire, Golhar and Waller (1996) studied firms between 100 and 3600 employees, the average number being 364. Badri, Davis and Davis (1995) studied firms with over 20 employees, $70 \%$ of them with less than 500 workers. As for Grandzol and 
Gershon (1998) and Quazi et al. (1998), although they do not set a minimum for their sample, $70 \%$ and $63 \%$ of the firms studied, respectively, have less than 500 employees, whereas in our study most of the firms have less than 500 workers (88\%).

Thus, although there are no differences in size, the number of large firms is a small one, which allows us to confirm that our measures supplement those developed by these authors and work well in European ISO 9000-certified small and medium firms. In this sense, it must be considered that ISO 9000 offers a standard applicable to any firm, region or country.

These measures assess TQM and, therefore, may be of use to managers in order to evaluate their quality practices, which may serve to identify both strengths and weaknesses. An awareness of these weaknesses should help to define areas for improvement, which would be the actions managers have to adopt in their certified firms in order to change the culture towards a TQM-oriented one. This model is easier to use and is less time and money-consuming than the EFQM model, and therefore constitutes an excellent starting point for TQM implementation.

Therefore, bearing in mind that experience has shown that some firms fail when they implement TQM (Boje and Winsor, 1993; Spector and Beer, 1994) and the implementation of TQM cannot be successful without the use of suitable quality management methods (Sitkin, Sutcliffe and Schoroeder, 1994; Wilkinson et al., 1998; Zhang, 2000) such as statistical techniques (Stuart, Mullins and Drew, 1996), managers of ISO 9000-certified small and medium firms that really want to progress towards a TQM culture, should implement the following factors, using the following methods:

- Leadership. Management's commitment to quality through communication with and motivation of employees. In this way, managers participate in quality activities and contribute improvements. 
Methods: top management commitment, quality council, support improvement activities, suggestion systems.

- Quality planning. Development of strategies for quality improvement through a definition of objectives at all organizational levels and periodic evaluation.

Methods: mision/vision statement, quality policy, quality goals, business plan, control and improvement of plans.

- Communication. Communicating these objectives to all members of the firm, so that there is a real commitment to these objectives and the employees really strive to attain them.

Methods: communicating objectives and strategies, work information.

- Training. General training level in the basic aspects of quality, regarding both managers and employees.

Methods: individual training plan, training for job requirements, general training programme.

- Specialized training. Training cannot stop at an initial level, and must be of a continued nature (Ishikawa, 1985). Therefore, it should also include training in problem-solving and teamwork, as a way to obtain higher employee involvement, which can lead in turn to higher employee involvement in improvement. Also, this is evaluated and recognized by the management.

Methods: Specialized training plan (statistical techniques), employee performance and satisfaction evaluation, recognition and reward systems.

- Suppliers management. Relation with suppliers in order to find the quality specifications demanded by the firm.

Methods: supplier audit, supplier evaluation, supplier training, agreed quality.

- Customer focus. Increasing contacts between the organization and customers, 
identifying their requirements, assessing their satisfaction and supporting activities improving customer satisfaction.

Methods: channels for processing customer complaints, identifying customer needs (surveys, market research, reports from vendors), customer satisfaction survey, aftersales service.

- Process management. Reflects how the organization controls and improves its processes by setting quality measures (level of customer satisfaction, quality cost ...). Methods: quality handbook, quality system procedures, work instructions, ISO 9001 certificate, use of indicators.

- Continuous improvement. Indicates whether the firm has created an organizational structure (quality committee, a person in charge of quality and work teams) responsible for this improvement by identifying actions through information management.

Methods: work teams, plan-do-check-act cycle, self-assessment activities (EFQM model ...), seven quality control tools, seven management tools.

- Learning. Measures whether the firm shows an interest in employees learning about all the basic aspects of the firm and its business by encouraging continuous learning and taking part in such learning in the eyes of the employees.

Methods: continuous training and education.

\section{Conclusions}

The research we propose here reflects the empirical results developing measures of TQM, verifying its reliability and validity. This study provides 10 measures of TQM (leadership, quality planning, communication, training -in general terms-, specialist training, suppliers management, customer focus, process management, continuous 
improvement and learning), as a model allowing managers to have a better understanding of quality management practices. By periodically using this model, it may serve to evaluate a firm's quality standards, finding those areas where improvement is necessary and, therefore, planifying the quality management effort.

From the results obtained, a reliable, valid instrument has been developed for measuring TQM, supplementing existing measures and focusing on certified European small and medium firms.

These factors do not perfectly fit the enablers in the EFQM model, but they are consistent both with the EFQM model and with the established quality management theory, proving that it is possible to develop a model for measuring these practices. Therefore, all small and medium firms wishing to go beyond the ISO-9000 requirements towards TQM must ensure a wide implementation of these 10 factors.

Although there is no unique model for a good TQM programme, our model less costly and easier to use than the EFQM model, which is why it may prove useful for an introduction to TQM, before using the EFQM model.

However, the limitation of this study is the criterion-related validity, which is statistically significant, although it is low as compared to the other works cited, which means that such a relationship exists, but it is not a high one. This would be due to the fact that many firms stated that their quality system had had a low impact upon their performance, because they had been working in this area for a short time (the average was almost 3 years of certification), which may justify such small connection. Also, we must consider most ISO certified companies does not seem to have a great understanding of the TQM phenomenon, they stay in a first level of TQM, which may justified a low incidence on the results

Finally, a firm’s quality performance is based on perceptions, not on actual results, 
and the number of firms in our study is slightly lower than in some of the works cited. Then, future studies should: a) consider the financial results and b) be carried out with a larger number of firms in Europe, and focusing on small and medium firms, in order to confirm these results and reinforce their applicability to this kind of firms, as a supplement to those studied applied to larger firms carried out by previous authors.

\section{References}

Abraham, M., Fisher, T., Crawford, J., 1997. Quality culture and the management of organization change, International Journal of Quality \& Reliability Management 14 (6) 616-636.

Ahire, S.L., Golhar, D.Y., Waller, M.A., 1996. Development and validation of TQM implementation constructs, Decision Sciences 27 (1) 23-56.

Allen, R.S., Kilmann, R.H., 2001. The role of the reward sytem for a total quality management based strategy, Journal of Organizational Change Management 14 (2) 110-131.

Anderson, J.C., Rungtusanatham, M., Schroeder, R.G., 1994. A theory of quality management underlying the Deming Management Method, Academy of Management Review 19 (3) 472-509.

Badri, M.A., Davis, D., Davis, D., 1995. A study of measuring the critical factors of quality management, International Journal of Quality \& Reliability Management 12 (2) 36-53.

Black, S., Porter, L.J., 1995. An empirical model for total quality management, Total Quality Management 6 (2) 149-164.

Black, S., Porter, L.J., 1996. Identification of the critical factors of TQM, Decision Sciences 27 (1) 1-21. 
Boje, D.M., Winsor, R.D., 1993. The resurrection of Taylorism: total quality management's hidden agenda, Journal of Organizational Change Management 6 (4) $57-70$.

Boyle, G.J., 1991. Does item homogeneity indicate internal consistency or item redundancy in psychometric scales?, Personality and Individual Differences 12 (March) 291-294.

Churchill, G.A., 1979. A paradigm for developing better measures of marketing constructs, Journal of Marketing Research 16 (February) 64-73.

ChurchilL, G.A., Peter, P., 1984. Research design effects on the reliability of rating scales: A meta-analysis, Journal of Marketing Research 21 (November) 98-104.

Cronbach, L.J., 1951. Coefficient alpha and the internal structure of test, Psychometricka 16 (September) 297-334.

Crosby, P.B. 1979. Quality is free, the art of making quality certain, Hodder \& Stoughton, New York.

Dale, B.G. 1999. Managing quality, Blackwell Publishers, Oxford.

Das, A., Handfield, R.B., Calantone, R.J., Ghosh, S., 2000. A contingent view of quality management-the impact of international competition on quality, Decision Sciences 31 (3) 649-690.

Deming, W.E. 1982. Quality, productivity and competitive position, MA, MIT Center for Advanced Engineering, Cambridge.

Deming, W.E. 1986. Out of the crisis, MA, MIT Center for Advanced Engineering, Cambridge.

Dervitsiotis, K.N., 1998. The challenge of managing organizational change: exploring the relationship of re-engineering, developing learning organizations and total quality management, Total Quality Management 9 (1) 109-122. 
Easton, G.S., Jarrel, S.L., 1998. The effects of total quality management on corporate performance, an empirical investigation, Journal of Business 71 (2) 253-307.

EFQM 2000. EFQM excellence model, European Foundation for Quality Management, Brussels.

Feigenbaum, A.V. 1991. Total quality control, McGraw-Hill, New York.

Flynn, B.B., Schroeder, R.G., Sakakibara, S., 1994. A framework for quality management research and associated measurement instrument, Journal of Operations Management 11 (4) 339-366.

Garvin, D.A. 1988. Managing quality. The strategic and competitive edge, The Free Press, New York.

Grandzol, J.R., Gershon, M., 1998. A survey instrument for standardizing TQM modelling research, International Journal of Quality Science 3 (1) 80-105.

Guilhon, A., Martin, J., Weill, M., 1998. Quality approaches in small or medium-sized enterprises: metodology and survey results, Total Quality Management 8 (8) 689701.

Hackman, J.R., Wageman, R., 1995. Total quality management, empirical, conceptual, and practical issues, Administrative Science Quarterly 40 (2) 309-341.

Hair, J.F., Anderson, R.E., Tatham, R.L., Black, W.C. 1995. Multivariate data analysis with reading, Prentice Hall, Englewood Cliffs, NJ.

Harber, D., Burgess, K., Barclay, D., 1993. Total quality management as a cultural intervention, an integrative review, International Journal of Quality \& Reliability Management 10 (6) 17-27.

Ishikawa, K. 1976. Guide to quality control, Asian Productivity Organization, Tokyo.

Ishikawa, K. 1985. What is total quality control? The Japanese way, Prentice Hall, London. Juran, J.M., 1986. Quality trilogy, Quality Progress August 14-24. 
Juran, J.M. 1988. On planning for quality, Collier Macmillan, London.

Kanji, G.K., 1998. Measurement of business excellence, Total Quality Management 9 (7) 633-643.

Kanji, G.K., Moura e Sá, P., 2002. Kanji’s business scorecard, Total Quality Management 13 (1) $13-27$.

Likert, R. 1967. The human organization: its management and value, McGraw-Hill, New York.

Madu, C.N., 1998. An empirical assessment of quality, research considerations, International Journal of Quality Science 3 (4) 348-355.

Nicolau, J.L., Sellers, R., 2002. The stock market's reaction to quality certification: empirical evidence from Spain, European Journal of Operational Research, 142 (3) 632-641.

Nunnally, J.C. 1978. Psychometric theory, 2d. ed., McGraw-Hill, New York.

Parasuraman, A., Zeithaml, V.A., Berry, L.L., 1985. A conceptual model of service quality and its implications for future research, Journal of Marketing 49 (4) 41-50.

Parasuraman, A., Zeithaml, V.A., Berry, L.L., 1988. SERVQUAL, a multiple item scale for measuring consumer perceptions of service quality, Journal of Retailing 64 (1) $12-40$

Peterson, R.A., 1994. A meta-analysis of Cronbach's coefficient alpha, Journal of Consumer Research 21 (September) 381-391.

Powell, T.C., 1995. Total quality management as competitive advantage, a review and empirical study, Strategic Management Journal 16 (1) 15-37.

Quazi, H.A., Jemangin, J., Kit, L.W., Kian, C.L., 1998. Critical factors in quality management and guidelines for self-assessment, the case of Singapore, Total Quality Management 9 (1) 35-55. 
Saraph, J.V., Benson, P.G., Schroeder, R.G., 1989. An instrument for measuring the critical factors of quality management, Decision Sciences 20 (4) 810-829.

Sitkin, S.B., Sutcliffe, K.M., Schroeder, R.G., 1994. Distinguishing control from learning in total quality management, a contingency perspective, Academy of Management Review 19 (3) 537-564.

Spector, B., Beer, M., 1994. Beyond TQM programmes, Journal of Organizational Change Management 7 (2) 63-70.

Stuart, M., Mullins, E., Drew, E., 1996. Statistical quality control and improvement, European Journal of Operational Research 88 203-217.

Szamosi, L.T., Duxbury, L., 2002. Development of a measure to assess organizational change, Journal of Organizational Change Management 15 (2) 184-201.

Van de Ven, A., Ferry, D. 1979. Measuring and assessing organizations, Wiley, New York.

Van der Wiele, A., Dale, B.G., Williams, A.R.T., 2000. ISO 9000 series and excellence models: fad to fashion to fit, Journal of General Management 25 (3) 50-66.

Van der Wiele, A., Williams, A.R.T., Dale, B.G., 2000a. ISO 9000 series registration to business excellence: the migratory path, Business Process Management Journal 6 (5).

Van der Wiele, A., Williams, A.R.T., Dale, B.G., 2000b. Total quality management: is it a fad, fashion, or fit?, Quality Management Journal 7 (2) 65-79.

Wilkinson, A., Redman, T., Snape, E., Marchington, M. 1998. Managing with total quality management: theory and practice, MacMillan, London.

Zhang, Z., 2000. Developing a model for quality management methods and evaluating their effects on business performance, Total Quality Management 11 (1) 129-137. 


\section{APPENDIX I}

Initial items used to measure the critical factors of quality management. Out of these original 37 items of the eight factors, we have asterisked those which were eliminated to improve reliability and validity of the measurement instrument.

\section{ELEMENTS OF QUALITY MANAGEMENT}

Please, indicate the level of implementation in your firm of each of the following elements in a scale from 1 (not implemented) to 7 (fully implemented).

\section{Leadership}

1* Higher management actively directs our quality management program

2 Managers actively communicate a quality commitment to the employees

3 Employees are encouraged to help implement changes in the organization

4 Managers and supervisors allow employees to make their own decisions

5 Managers and supervisors motivate their employees and help them perform at a high level in their tasks

\section{Quality planning}

1 Development and implementation of strategies and plans based on data concerning customers' requirements and the firm's capabilities

2 The management sets objectives for managers

3 The management sets objectives for all employees

4 The management communicates its strategy and objectives to the whole staff

5 Management involves the employees in the setting of its objectives and plans

6 Results are evaluated by comparing them to planned results, in order to make improvements

\section{Employee management}

1 Management are trained in quality principles

2 Employees are trained in quality principles

3 Employees are trained in problem-solving skills

4 Employees are trained in teamwork

5 Employees' performance is measured and recognized in order to support quality programs

6* There is bottom-up, top-down and horizontal communication among all the staff

\section{Suppliers management}

1 Closer work with suppliers

2 Requirements are placed upon suppliers in order to find quality specifications

3* The management encourages the usage of few suppliers, emphasizing quality rather than price

\section{Customer focus}

1 Increased personal contacts between the organization and customers

2 Customers' requirements are used as the basis for quality

3 Managers and supervisors support activities improving customer satisfaction

\section{Process management}

1 Continuous control and improvement of key processes

2 Preventing faulty products/services is a strong practice in this organization

3 The processes used in this organization include quality measures

4 The employees involved in different processes know how to evaluate them 


\section{Continuous improvement}

1 Program aimed at finding time and cost losses in all internal processes

2 This organization reinforces continuous study and improvement of all its products, services and processes

3 Use of specific organizational structures (quality committee, work teams) to support quality improvement

4 Identification of areas for improvement

5 Information management aimed at supporting quality management (analysis of data regarding business

performance, cost and financial aspects in order to support the development of improvement priorities)

\section{Learning}

1 Managers and supervisors declare that all employees are trained to help them understand how and why the organization performs

2 Most employees in this organization possess sufficient knowledge of the basic aspects of our sector

3 Most employees in this organization understand the basic processes used to create our products/services

4 Higher management has developed an environment helping towards on-the-job training

5 Managers and supervisors participate in specialist training

\section{APPENDIX II}

\section{QUALITY MANAGEMENT RESULTS}

Please, answer the following questions within a scale from 1 (I completely disagree) to 7 (I completely agree).

\section{Customer satisfaction}

1 This organization is not concerned about collecting information from its customers in order to measure their satisfaction

2 Customer satisfaction has historically shown improvements

3 This organization has implemented a process to listen to and solve customer complaints

Please, indicate for each question within a scale from 1 (I completely disagree) to 7 (I completely agree) how your quality program has influenced your firm's performance

1 Our financial results have been excellent

2 Our quality program has increased our revenue

3 Our quality program has increased our yield

4 Our quality program has improved our competitive position

5 Our quality program has improved our performance in general

6 Our quality program has had a negative impact upon our profitability

7 We could have done better (i.e. obtained better financial results) without a quality program 


\section{TABLES}

Table I. Empirical research of quality management

\begin{tabular}{llc}
\hline \multicolumn{1}{c}{ Authors } & \multicolumn{1}{c}{ Critical factors identified } & Size of the firms \\
\hline Saraph, Benson and Schroeder (1989) & 8 factors with 66 items & $>1000$ employees \\
Badri, Davis and Davis (1995) & 8 factors with 66 items & employees \\
Black and Porter (1995, 1996) & 10 factors with 32 items & Not indicated \\
Ahire, Golhar and Waller (1996) & 12 factors with 50 items employees \\
Grandzol and Gershon (1998) & $\begin{array}{l}7 \text { exogenous factors with 39 items and 6 endogenous } \\
\text { factors with 23 items }\end{array}$ & All sizes \\
Quazi et al. (1998) & 16 factors with 78 items & All sizes
\end{tabular}


Table II. Number of certified firms according to number of employees

\begin{tabular}{|c|c|c|c|c|c|c|c|c|c|}
\hline & \multicolumn{7}{|c|}{ Number of employees } & \multicolumn{2}{|c|}{$\begin{array}{l}\text { Sector (Standard } \\
\text { Industrial } \\
\text { Classification -SIC-) }\end{array}$} \\
\hline & \multicolumn{2}{|c|}{ Small } & \multicolumn{2}{|c|}{ Medium } & \multicolumn{2}{|c|}{ Large } & \multirow[b]{2}{*}{ Total } & \multirow[t]{2}{*}{ Industry } & \multirow[t]{2}{*}{ Services } \\
\hline & $<20$ & $20-49$ & $50-99$ & $100-250$ & $>250$ & $>500$ & & & \\
\hline No. of firms & 17 & 17 & 27 & 24 & 8 & 13 & 106 & & \\
\hline Total & \multicolumn{2}{|c|}{34} & \multicolumn{2}{|c|}{51} & \multicolumn{2}{|c|}{21} & 106 & 63 & 43 \\
\hline Total (percentage) & \multicolumn{2}{|c|}{$32 \%$} & \multicolumn{2}{|c|}{$48 \%$} & \multicolumn{2}{|c|}{$20 \%$} & $100 \%$ & $59 \%$ & $41 \%$ \\
\hline
\end{tabular}


Table III. Elements of the EFQM model and critical factors identified

\begin{tabular}{|c|c|c|c|}
\hline $\begin{array}{c}\text { Enablers } \\
\text { (EFQM model) }\end{array}$ & Critical factors & $\begin{array}{l}\text { No. of } \\
\text { items }\end{array}$ & Source \\
\hline Leadership & Leadership & 5 & $\begin{array}{l}\text { Strategic quality management (Black and Porter, 1995, 1996) } \\
\text { Executive commitment (Powell, 1995) } \\
\text { Leadership (Grandzol and Gershon, 1998) } \\
\text { EFQM model }\end{array}$ \\
\hline $\begin{array}{l}\text { Planning and } \\
\text { strategy }\end{array}$ & $\begin{array}{l}\text { Quality } \\
\text { planning }\end{array}$ & 6 & $\begin{array}{l}\text { Role of divisional top management and quality police (Saraph, } \\
\text { Benson and Schroeder, 1989) } \\
\text { Operational quality management (Black and Porter, 1995, 1996) } \\
\text { Corporate quality culture (Black and Porter, 1995, 1996) } \\
\text { Top management commitment (Ahire, Golhar and Waller, 1996) } \\
\text { EFQM model }\end{array}$ \\
\hline $\begin{array}{l}\text { Employee } \\
\text { management }\end{array}$ & $\begin{array}{l}\text { Employee } \\
\text { management }\end{array}$ & 6 & $\begin{array}{l}\text { Training (Saraph, Benson and Schroeder, 1989; Powell, 1995) } \\
\text { Employee relations (Saraph, Benson and Schroeder, 1989) } \\
\text { People and customer management (Black and Porter, 1995, 1996) } \\
\text { Employee empowerment (Ahire, Golhar and Waller, 1996) } \\
\text { Employee training (Ahire, Golhar and Waller, 1996) } \\
\text { EFQM model }\end{array}$ \\
\hline Resources & $\begin{array}{l}\text { Suppliers } \\
\text { management }\end{array}$ & 3 & $\begin{array}{l}\text { Supplier quality management (Saraph, Benson and Schroeder, 1989; } \\
\text { Ahire, Golhar and Waller, 1996) } \\
\text { Supplier partnership (Black and Porter, 1995, 1996) } \\
\text { Closer to suppliers (Powell, 1995) } \\
\text { Internal/external cooperation (Grandzol and Gershon, 1998) } \\
\text { EFQM model }\end{array}$ \\
\hline Processes & $\begin{array}{l}\text { Customer } \\
\text { focus }\end{array}$ & 3 & $\begin{array}{l}\text { People and customer management (Black and Porter, 1995, 1996) } \\
\text { Customer satisfaction orientation (Black and Porter, 1995, 1996) } \\
\text { Closer to customer (Powell, 1995) } \\
\text { Customer focus (Ahire, Golhar and Waller, 1996; Grandzol and } \\
\text { Gershon, 1998) } \\
\text { EFQM model }\end{array}$ \\
\hline & $\begin{array}{l}\text { Process } \\
\text { management }\end{array}$ & 4 & $\begin{array}{l}\text { Process management (Saraph, Benson and Schroeder; 1989; } \\
\text { Grandzol and Gershon, 1998) } \\
\text { Quality improvement measurement systems (Black and Porter, 1995, } \\
\text { 1996) } \\
\text { EFQM model }\end{array}$ \\
\hline & $\begin{array}{l}\text { Continuous } \\
\text { improvement }\end{array}$ & 5 & $\begin{array}{l}\text { Quality date and reporting (Saraph, Benson and Schroeder, 1989) } \\
\text { Teamwork structures for process improvement (Black and Porter, } \\
\text { 1995, 1996) } \\
\text { Quality improvement measurement systems (Black and Porter, 1995, } \\
\text { 1996) } \\
\text { Open organization (Powell, 1995) } \\
\text { Process improvement (Powell, 1995) } \\
\text { Continuous improvement (Grandzol and Gershon, 1998) } \\
\text { EFQM model }\end{array}$ \\
\hline Learning & Learning & 5 & Learning (Grandzol and Gershon, 1998) \\
\hline
\end{tabular}


Table IV. Alpha coefficient and alpha coefficient of the scale after eliminating one item

\begin{tabular}{|c|c|c|c|c|c|c|c|c|}
\hline Factor & $\begin{array}{c}\text { Item } \\
\text { number }\end{array}$ & $\begin{array}{l}\text { Alpha after } \\
\text { eliminating } \\
\text { one item }\end{array}$ & Factor & $\begin{array}{c}\text { Item } \\
\text { number }\end{array}$ & $\begin{array}{l}\text { Alpha after } \\
\text { eliminating } \\
\text { one item }\end{array}$ & Factor & $\begin{array}{c}\text { Item } \\
\text { number }\end{array}$ & $\begin{array}{c}\text { Alpha after } \\
\text { eliminating } \\
\text { one item }\end{array}$ \\
\hline & 1 & 0.77 & & 1 & 0.74 & & 1 & 0.71 \\
\hline & 2 & 0.67 & & 2 & 0.74 & & 2 & 0.67 \\
\hline Leadership & 3 & 0.69 & Quality & 3 & 0.74 & Employee & 3 & 0.66 \\
\hline \multirow[t]{4}{*}{$\alpha=0.76$} & 4 & 0.74 & planning & 4 & 0.70 & management & 4 & 0.63 \\
\hline & 5 & 0.69 & $\alpha=0.77$ & 5 & 0.74 & $\alpha=0.72$ & 5 & 0.68 \\
\hline & & & & 6 & 0.74 & & 6 & 0.71 \\
\hline & 1 & 0.41 & & 1 & 0.48 & & 1 & 0.51 \\
\hline Suppliers & 2 & 0.21 & Customer focus & 2 & 0.47 & Process & 2 & 0.62 \\
\hline management & 3 & 0.62 & & 3 & 0.40 & management & 3 & 0.51 \\
\hline \multirow[t]{2}{*}{$\alpha=0.52$} & & & $\alpha=0.54$ & & & $\alpha=0.63$ & 4 & 0.60 \\
\hline & 1 & 0.73 & & 1 & 0.77 & & & \\
\hline Continuous & 2 & 0.75 & & 2 & 0.78 & & & \\
\hline improvement & 3 & 0.73 & Learning & 3 & 0.79 & & & \\
\hline \multirow[t]{2}{*}{$\alpha=0.76$} & 4 & 0.70 & $\alpha=0.82$ & 4 & 0.77 & & & \\
\hline & 5 & 0.69 & & 5 & 0.81 & & & \\
\hline
\end{tabular}


Table V. Summary of the factor matrix for each measure

\begin{tabular}{lcccc}
\hline \multicolumn{1}{c}{ Construct } & KMO & $\begin{array}{c}\text { Item loading range } \\
\text { for factor 1 }\end{array}$ & Eigenvalue & $\begin{array}{c}\text { Percentage variance } \\
\text { explained by factor 1 }\end{array}$ \\
\hline Leadership & 0.78 & 0.68 to 0.81 & 2.36 & 58.89 \\
Suppliers management & 0.51 & 0.86 to 0.86 & 1.460 & 72.50 \\
Customer focus & 0.61 & 0.69 to 0.72 & 1.48 & 50.22 \\
Process management & 0.61 & 0.61 to 0.79 & 1.93 & 48.21 \\
Continuous improvement & 0.82 & 0.64 to 0.79 & 2.56 & 51.01 \\
Learning & 0.78 & 0.68 to 0.82 & 2.96 & 59.07 \\
\hline
\end{tabular}


Table VI. Rotated factor matrix of the quality planning factor Items quality planning factor

F1

1. Development and implementation of strategies and plans based on data 0.55 concerning customers' requirements and the firm's capabilities

2. The management sets objectives for managers

0.83

3. The management sets objectives for all employees

0.80

4. The management communicates its strategy and objectives to the whole staff

5. Management involves the employees in the setting of its objectives and plans

6. Results are evaluated by comparing them to planned results, in order to make improvements

Eigenvalue 
Table VII. Rotated factor matrix of the employee management factor

\begin{tabular}{llcc}
\hline \multicolumn{1}{c}{ Items employee management factor } & $\mathrm{F} 1$ & $\mathrm{~F} 2$ \\
\hline 1. & Management are trained in quality principles & 0.92 \\
2. & Employees are trained in quality principles & 0.86 \\
3. Employees are trained in problem-solving skills & 0.93 & \\
4. Employees are trained in teamwork & 0.95 & \\
5. Employees' performance is measured and recognized in order to support quality & 0.58 & \\
$\quad$ programs & & 2.12 & 1.62 \\
\hline Eigenvalue & 45.37 & 32.29 \\
Percentage variance explained by factor & 45.37 & 77.66 \\
Percentage total variance explained & & \\
\hline
\end{tabular}


Table VIII. Measures of TQM

\begin{tabular}{ll}
\hline \multicolumn{1}{c}{ Critical factor } & \multicolumn{1}{c}{ Item number } \\
\hline Leadership & $2,3,4,5$ \\
Quality planning & $1,2,3,6$ \\
Communication & 4,5 \\
Training & 1,2 \\
Specialist training & $3,4,5$ \\
Suppliers management & 1,2 \\
Customer focus & $1,2,3$ \\
Process management & $1,2,3,4$ \\
Continuous improvement & $1,2,3,4,5$ \\
Learning & $1,2,3,4,5$ \\
\hline
\end{tabular}

